\title{
On the Sensitivity Ratio of Clay
}

\author{
By \\ Shin'ichi Yamaguchi \\ Physical Department, Defence Academy, Yokosulea
}

\begin{abstract}
Summary
By taking as sample Osaka alluvial clay which is called Kaolinite and the clay gathered from Okuramura land creep region, Yamagata prefecture, the author studied the sensitivity of clay. As the result, we could comprehend that it is clue to the special water in case of the former clay, while in case of the latter clay it is due to the difference in the arrangement of the scale-like particles.
\end{abstract}

\section{$\S 1$. Introduction}

The clay generally lessens its strength only by remolding, without changing its water content. The ratio $\mathrm{Sv} / \mathrm{Sr}$, in which $\mathrm{Sv}$ is the strength of the undisturbed clay and $\mathrm{Sr}$ is the strength of the same clay fully remolded, with its water content unchanged, is called the sensitivity ratio. Since by remolding the clay changes its nature and the critical point of shear failure becomes obscure, the strength of the remolded clay $\mathrm{Sr}$ is determined from the stress for that strain which causes shear failure of the undisturbed clay. The sensitivity ratio varies considerably with the kind of clay, ranging from 2 to 500 . So, the clarification of this property is important not only for soil mechanics, but also for geophysics, because several natural phenomena are associated with the disturbed soil. Two theories have been advanced to explain the differences in the property: the theory of $\mathrm{A}$. Casagrande and that of $\mathrm{K}$. Terzaghi.

Casagrande's theory is as follows: in a clay/silt mixture those clay particles which enter the lesser spaces between the silt particles are consolidated by higher stresses than those which lie in the larger spaces. This 'bond clay' possesses considerable strength. When such soils are remolded, the total strength decreases, because the strength due to bonding is destroyed.

$\mathrm{K}$. Terzaghi's theory states that: if the soil is consolidated for a sufficient time, the stresses squeeze out the absorbed water, so that the particles come into contact with one another and at such point the true cohesion force functions. If any pressure applied from the outside is removed, the absorbed water returns gradually to the contact points of the particles, but it takes a fairly long time to do so completely. When the soil is remolded, the total strength becomes less, because the distance between the particles becomes greater.

Recently, O. Morretto(1) demonstrated that the remolded clay put in a state of rest gradually recovered its strength, and the strength ratio of the remolded clay after resting for the remolded clay became larger as the liquidity index of the clay sample became larger. Newland et al(2) showed that the sensitivity ratio becomes smaller as preconsolidation pressure is larger. Recent experiment by the author indicates that a paste which is consisted of the microparticles of clay below $1 \mu$ when in a state of rest increases its strength just in the same way as does the remolded clay containing all clay and silt particles.

According to Terzaghi's theory, the strength of the remolded clay declines as the time of resting increases. And according to Casagrande's theory, the strength of a paste which consists of the microparticles of clay below $1 \mu$ does not change when in a state of resting. Therefore both theories cannot always explain those experimental results.

Thus, the author attempted to clarify the problem of sensitivity. The samples he 
used were taken from Osaka alluvial clay which is chiefly consisted of kaollinite and from Okuramura clay of Yamagata prefecture which is chiefly consisted of montmorillonite.

\section{§2. Osaka Alluvial Clay}

\section{( ) Sensitivity}

Many completely remolded specimens, $3.4 \mathrm{~cm}$ in diameter and $8 \mathrm{~cm}$ in height, were made and each was placed in a rubber sleeve closed with latex. Then, varying the period of resting for each specimen, their strengths were tested. Unconfined compression test

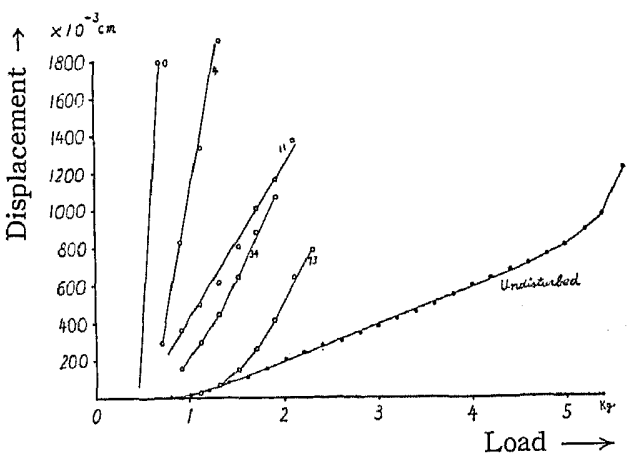

Fig. 2.1 Stress-strain relation in stress control test (6A6-6, 916-S) Figures in the diagram indicate resting days.

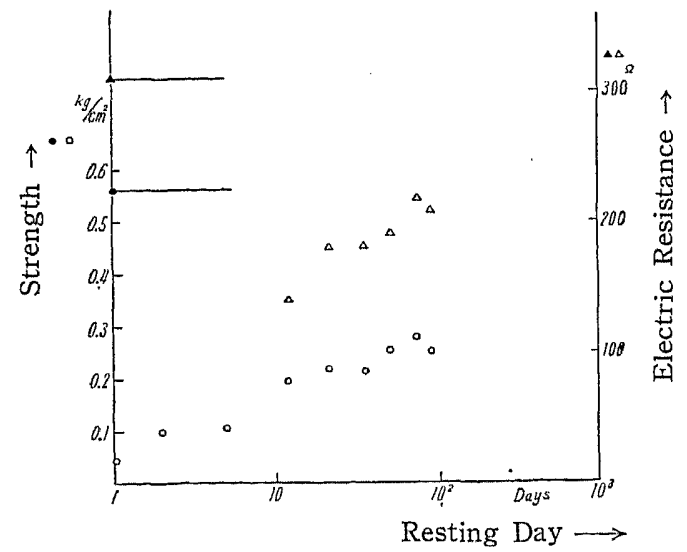

Fig. 2.2 Recovery of strength and of electric resistance.

\begin{tabular}{|l|c|c|}
\hline & Strength & Resistance \\
\hline Undisturbed Clay & - & $\Delta$ \\
\hline Remold Clay & 0 & $\triangle$ \\
\hline
\end{tabular}

was carried out in the controlled stress manner. The rate of increase of stress was $200 \mathrm{gr} / \mathrm{cm}^{2}$ min. The sensitivity ratio determined in this way was about 10 . As the recovery of strength proceeds gradually, merely about one half of the strength was recovered within two months. Part of the results of the controlled stress unconfined compression test is shown in Fig. 2.1; and the recovery of strength, in Fig. 2.2.

\section{(2) Void Ratio and Electric Double Potential of Particle Surface}

Of the clay just before being remolded, of the clay immediately after being remolded with its water content unchanged and of the same clay after various period restings, the strength, void ratio and electric double sheet potential of particle surface were measured.

Void ratio should be calculated indirectly from the measured values of water content, specific gravity of soil particle and wet density of the clay. However, in the mensuration of wet density some errors may easily be accompanied due to the measurement of volume. Therefore, to obtain the more accurate value in the measurement of volume, the author adopted the following method; a loaf of clay wrapped with paraffine was steeped into water and then its bouyancy was measured.

Electric double sheet potential of particle surface was calculated from the electroosmotic equation,

$$
V=\zeta r^{2} H D D / 4 \eta
$$

in which $V$ is the volume of water, passing through a cross section of the cylindrical tube with the uniform diameter, per unit time and $\zeta$ is electric potential difference between the fixed plane and the movable plane of the double sheet, $\eta$ is the viscosity of water, $r$ is the inner radius of the tube, $D$ the dielectric constant of water and $H$ is voltage gradient between the electric poles.

As both $D$ and $\eta$ being already known and $r^{2}$ possible to be estimated from the porosity by considering the void in the soil as a vacant, cylindrical tube, $\zeta$ can be calculated if $H$ and $V$ are measured. Of the values of $\zeta$ thus obtained, there was hardly recognized 
any difference between the undisturbed clay and the remolded clay.

The void ratio of the remolded specimen proves a little larger than that of the undisturbed specimen.

On the other hand, from the linear relationship of logarithums both of the strength and of water content of the saturated undisturbed specimen,(:) the relation between the void and the strength can be determined. As the result, it was comprehended that the decrease of strength by remolding couldn't be explained according to such a small difference of the void ratio.

\section{(3) Electric Resistance}

Preparing the specimen in the same way as in the unconfined compression test and placing the electric poles, which are made of stainless steel and are insulated from the compression test apparatus, at the both ends, its resistance was measured by means of a Kohlraush bridge. As resistance does not change with frequency of the alternating electric current in the range from 50 to 10,000 cycles, 10,000 cycle alternating current was used. When the loads were put on the specimens during the experiment, some change appeared in the electric resistance. This may be interpreted due to a change of the contact area between the electric pole and specimen, so in carrying

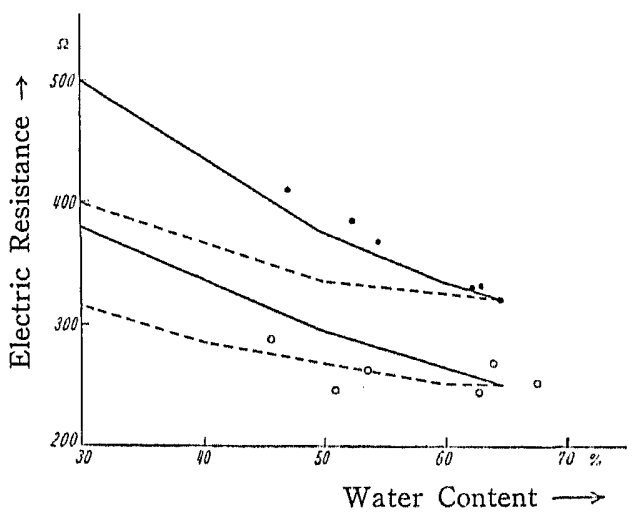

Fig. 2.3 Relation between electric resistance and water content (6A6-6, 920-S) Undisturbed clay Remold clay

Theoretical curve $\left\{\begin{array}{l}\text { Volume is constant } \\ \text { Air is not included }\end{array}\right.$ out the experiment, a load placed on the specimens was increased until the apparent electric conductivity reached saturation.

Many measurements were taken thus, and one example is shown in Fig. 2.3. Since the specimen measured in the loaded state differs from the original one both in diameter and in height, the adopted value is corrected to the original dimensions. If the size of the measured specimen is $\mathrm{dcm}$ in diameter, $1 \mathrm{~cm}$ in height and its electric resistance is $R$, the converted electric resistance $R^{\prime}$ in terms of the standard size of the specimen must be shown as follows;

$$
R^{\prime}=\frac{8 d^{2}}{3.4^{2} 1} R
$$

In considering the result, we assume at first that the electric conductivity is concerned only with the contained water and that the clay particle is nonconductive body. By doing so, we determine the electric resistance for the volume-ratio of water in the clay alone.

Thence, the following equation can be obtained;

$$
1 / R_{s s}=1 / R_{s w}\left(\boldsymbol{r}_{w}\right)^{2 /: 1}
$$

where $R_{s w}$ and $R_{s:}$ are respectively the electric resistances, per unit area of the vertical section and per unit length, of the contained water and of the clay, and $r_{u}$ is the volume ratio of contained water in the clay. When the water content is $65 \%$, the clay consists merely of the particle and water, but if the water content becomes less, two extreme cases ought to be considered: one in which the volume shrinks as much as the water content decreases and air does not enter into the specimen, and the other in which as much air enters as water is lost and the volume does not shrink. The relation between the water content and the electric resistance for these two extreme cases calculated from the equation (2.1) is entered in Fig. 2.3.

The actual measured values when desiccated naturally in the atmosphere, indicate that the result accords, in case of the remolded clay, with the former instance where air does not enter into the specimen and the volume shrinks and, in case of the undisturbed 
clay, with the latter instance where the volume does not shrink and air enters. Measuring the relation between the water content and the void ratio for the case in which the specimen is desiccated naturally in the atmosphere, we find it to be as stated. (Fig. 4.1).

Here, we discover a fairly distinct difference between the remolded and the undisturbed clays. That there is some difference in the electric resistance between the disturbed specimen and the remolded specimen, even if the water content or the void ratio of both specimens may be equal, is probably resulted from the fact that there is difference in the specific electric resistance of contained water between the two. But, scrutinizing Fig. 2.3 more closely, we may perceive that, if the water content is transferred about $20 \%$, the volume-constant curves of the remolded specimen and of the undisturbed specimen overlap. This suggests that in the undisturbed sample there is about $20 \%$ water which evaporates in the desiccator, yet acts as a non-conductive body to electricity and that between the undisturbed clay and the remolded clay there is no difference in the electric conductivity of water excluding $20 \%$ portion afore-mentioned.

Of these two conclusions thus far delivered, the author advanced to investigate which is more appropriate, from another angle in the following chapter.

\section{(4) Specific Heat Capacity}

The specific heat of clay is measured in the following ways: the samples, which are all made $7 \mathrm{~cm}$ in diameter, 7 or $8 \mathrm{~cm}$ high and $500 \mathrm{gr}$ in weight, are covered with latex and placed in $1,000 \mathrm{gr}$ of water and heated. For heating, the electric heater $(100 \mathrm{v}, 60 \mathrm{w})$ was used. And the supplied electric voltage, being increased to $100 \mathrm{v}$ through the stabilizer beforehand, then dropped to $50 \mathrm{v}$ by the transformer. By doing so, the rate of the increase of temperature becomes $2-3^{\circ} \mathrm{C}$ per 20 min., and both clay and water are heated almost equally.

Then, the following equation, where $C v$, $C w$ and $C c$ are each respectively the specific heats of the vessel, water and the clay, and the given thermal energy is $E n$, the rise of temperature produced is $T_{1}$, is obtained;

$$
E n_{1} / T_{1}=C v+C w+C c
$$

And in the experiment performed exactly in the same way without the clay specimen, the equation

$$
E n_{2} / T_{2}=C v+C w
$$

is derived, in which $T_{2}$ is the rise of temperature. Here, from (2.2) and (2.3) $C c$ can be obtained.

Next, by determining the water content of the clay and subtracting the heat capacity of the contained water, provided that water contained in the clay is invariably common, we can obtain the specific heat capacity of the clay particles alone. As is shown in Fig. 2.4, the specific heat of the undisturbed sample is twice or thrice as much as that of the remolded sample in spite of the fact that there is no difference in the specific heat of the clay particles.

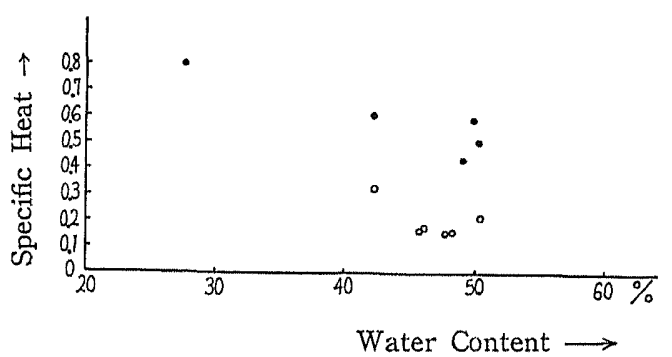

Fig. 2.4. Specific heat of clay particle (Taishobashi, No. 111, 20.87-21.76, 4-16A No. 106 B, $\mathrm{m}_{16.15-17.12}^{\mathrm{m}}$
- Undisturbes clay
Remolded clay

These values seem to be too high in the case of the undisturbed sample and also, when compared with the specific heat of rock or of sand, 0.17-0.23.

These results come forth from estimating the specific heat capacity of all contained water in the undisturbed clay as 1.0, and yet, in reality, the special water as was already mentioned in (2.3) and the common water of which specific heat capacity is 1.0 are both comprized in the contained water of the undisturbed clay. Therefore, by presuming 
that the special water turns into the common water as temperature rises and that in this process much latent heat is needed, we can elucidate the difference of heat capacity between the undisturbed clay and the remolded one.

If it be the case, the part of the special water must revert to common water when temperature rises, and, accordingly, the electric resistance must decrease inversely with the rise of temperature. In Fig. 2.5 the experimentally obtained relation between temperature and the electric resistance is shown.

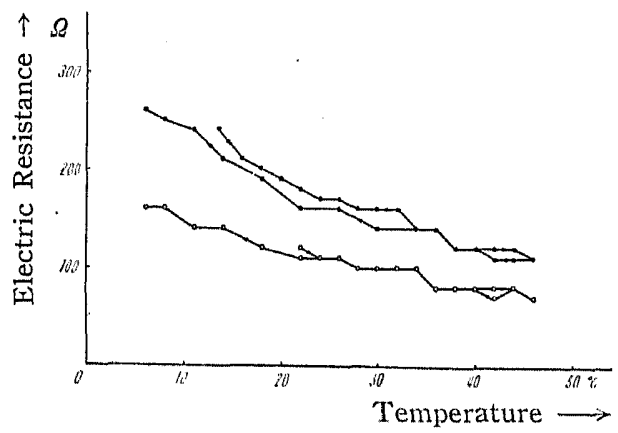

Fig. 2.5 Relation between electric resistance and temperature

Undisturbed clay (water content $38.9 \%$ )

Remold clay

( ) (water content $39.1 \%$ )

It is found, as we expected, that the electric resistance decreases as temperature rises. Yet this process is reversible, so the electric resistance increases again if temperature falls. Of course, it is well known that the electric resistance of solution itself decreases as temperature rises. So, the specimens of the undisturbed clay, of the remolded clay and of the paste which is made from the dried and powdered clay particles and pure water, were investigated as for the relation between temperature and the electric resistance. The relation between the ratio of electric resistance at various temperature and that at $18^{\circ} \mathrm{C}$, is shown in Fig. 2.6. Except in case of the undisturbed sample, every line lies almost on the same curve.

Examining this relation by taking the

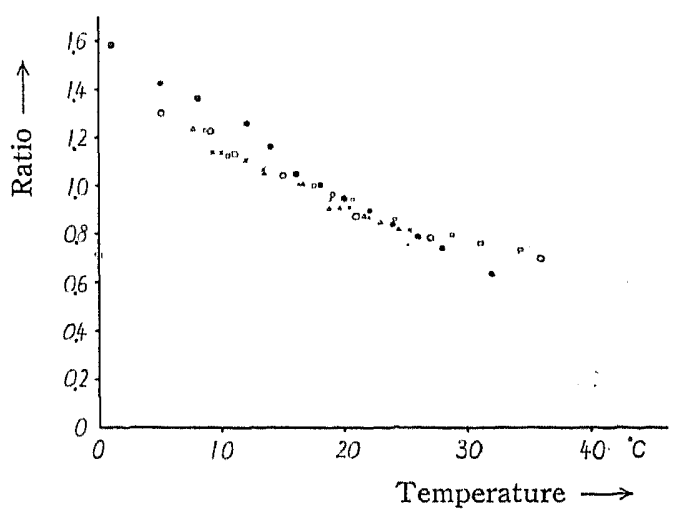

Fig. 2.6 Relation between electric resistance ratio $R / R_{0}$ and temperature. Where $R_{0}$ is the resistance at $18^{\circ} \mathrm{C}$.

Undisturbed Water Content 40\%

Remolded $\bigcirc$ Water Content 40\%

Paste $\square$ Water Content $67 \%$

Paste $\triangle$ Water Content $100 \%$

Dispersed system $\times$ Water Content $500 \%$

logarithm of electric resistance as the axis of ordinate and the reciprocal of absolute temperature as the axis of abscissa, we obtain a straight line relation and the value of its gradient.

Since, except in case of the undistrubed clay, the straight line relation and the value of its gradient are in accord with the wellknown relation between the viscosity of water $(\eta)$ and temperature, $\eta \alpha \exp (-E w / k T)$ in which $k$ is Boltzmann constant and $E w$ is is activation energy of water, we can assume that the change of electric resistance by temperature is caused by the change of viscosity coefficient of the soil moisture by temperature.

Next, we obtained the ratio of electric resistance at $8^{\circ} \mathrm{C}$ to that at $18^{\circ} \mathrm{C}$ for each water content, as shown in Fig. 2.7. As clearly shown in this figure, the case of undisturbed clay is distinguishable from the other cases.

The change of electric resistance by temperature in the paste or in the remolded clay, which is observed from the figure to occupy about $80 \%$ of the change of electric resistance by temperature in the undisturbed clay, was ascertained as caused by the change 


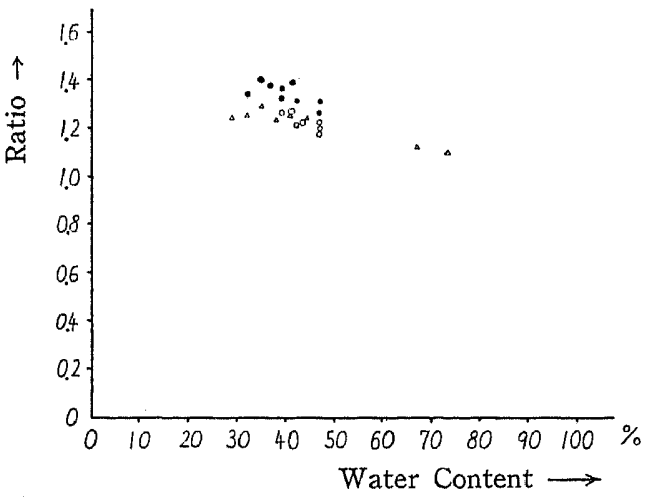

Fig. 2.7 Relation between electric resistance ratio (at $18^{\circ} \mathrm{C}$ to at $8^{\circ} \mathrm{C}$ ) and water content.

- Undisturbed $\bigcirc$ Remolded $\triangle$ Paste

of electric resistance by temperature in the soil moisture. Accordingly it is evident that some one fifth of the change of electric resistance by temperature in the undisturbed clay is owing to the change of special water into common water.

Then, the latent heat of special water can be calculated as follows: if the fresh saturated undisturbed clay, which keeps a water content of $40 \%$, is heated from $8^{\circ} \mathrm{C}$ to $18^{\circ} \mathrm{C}$, the electric resistance of the specimen falls from $250 \Omega$ to $190 \Omega$. (cf. Fig. 2.5)

However, this change is not only due to the decrease of special water, but to the increase of electric conductivity of common water also.

Nevertheless, it may be considered that the change of resistance due to the decrease of special water alone is approximately (250$190) \Omega / 5=12 \Omega$. This change, $12 \Omega$, is equivalent to the change of $2 \%$ of special water into common water. (cf. Fig. 2.3) From the above consideration it is estimated that a rise of $1^{\circ} \mathrm{C}$ in temperature produces a $0.2 \%$ change of special water into common water. Since the difference of the specific heats between the undisturbed and clay the remolded clay (water content both $40 \%$ ) is about $0.3-0.1$, not merely from Fig. 2.4 but also in consideration of the experimental result in (2.9) we can estimate that the latent heat of special water is about 150-50 cal/gr, [(0.3 0.1)-0.002].

\section{(5) Iufluence of Temperature on the Strenglh of Clay}

In the previous chapter, that there was found difference in the quantity of special water between the undisturbed clay and the remolded clay was delivered.

So, the author experimented if the difference between the undisturbed clay and the remolded one could be interpreted according to the quantity of special water.

As the temperature of the undisturbed clay increases, the contained special water turns into common water and displays the same effect as the increase of water content, so that the strength has to diminish. While in case of the remolded clay, however, it can be expected that the strength should rarely have any relation to temperature.

By leading water in the pressure chamber of the triaxial shear equipment into the capacious thermostat, the clay specimen equipped in the triaxial shear equipment was made surrounded by water at some constant temperature and was keeping the same temperature as that of water. About the clay specimen thus settled, stress controlled unconfined compression test was performed without giving any pressure to water in the pressure chamber. The size of the specimen and the rate of stress increase is quite the same as were refered to in 2.1. The thus obtained relation between temperature and the strength is, in case of the remolded clay, shown in Fig. 2.8 and in case of the un-

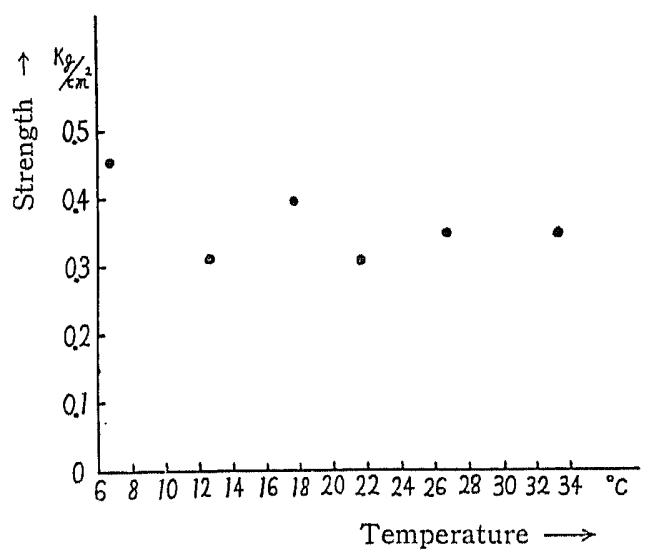

Fig. 2.8 Relation between strength and tem. perature of remolded clay (Taishobashi 208, 16. m16-17.m06A, Water content 49.5\%) 


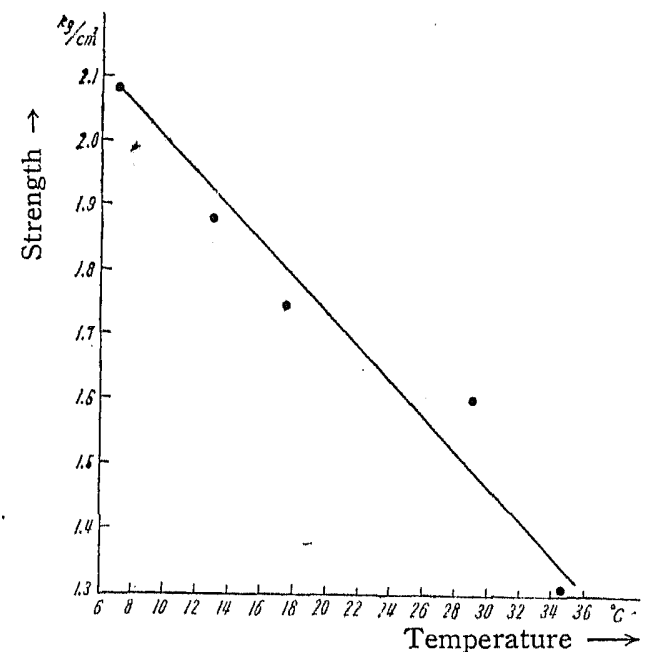

Fig. 2.9 Relation between strength and temperature of undisturbed clay (Taishobashi 208, 16.16-17.06, Water content 49.5\%)

disturbed clay is shown in Fig. 2.9. From Fig. 2.9, we can observe that the strength of undisturbed clay lessens from $2.1 \mathrm{~kg} / \mathrm{cm}^{2}$ to $1.3 \mathrm{~kg} / \mathrm{cm}^{2}$ when temperature increases from $6^{\circ} \mathrm{C}$ to $36^{\circ} \mathrm{C}$. On the other hand, it is also estimated from Fig. 2.5 that the electric resistance of clay specimen diminishes from $260 \Omega$ to $140 \Omega$ by the same amount of the increase of temperature. As was elucidated in 2.4, we may suspect that, out of the whole decrease of electric resistance of the undisturbed clay due to the rise of temperature, one fifth of its decrease is caused by special water tranforming into common water. Therefore, it can be considered that, in this case, the increase of common water is worth one fifth of $(260-140)=120 \Omega$, i.e. $24 \Omega$. However, that the increase of water content worth $24 \Omega$ of the decrease of electric resistance is $4 \%$ is attained according to the relation between the water content and electric resistance of Fig. 2.3. The estimation thus indirectly taken that, by $4 \%$ of the increase of water content, the strength changes from $2.1 \mathrm{~kg} / \mathrm{cm}^{2}$ to $1.3 \mathrm{~kg} / \mathrm{cm}^{2}$ is well coincident with the strength and was content relation taken from the direct measurement of the effect of water content upon the strength. (:)

And from the relation between the water content and strength we may perceive that, if at $25^{\circ} \mathrm{C}$, in order to fall $1.6 \mathrm{~kg} / \mathrm{cm}^{2}$ of strength of the undisturbed clay of $0.4 \mathrm{~kg} / \mathrm{cm}^{2}$ of strength of the remolded clay at the same water content, it is necessary to increase $18 \%$ of water content. This fact is equivalent to that, as was related upon the electric resistance of Fig. 2.3, if the electric resistance and watercontent relation curve of the undisturbed clay is shifted towards an origin by $20 \%$ of water content, it lies upon the same relation curve of the remolded clay. Assuming that the special water is nonconductive body and comparing as for the quantity of common water alone, we can estimate from the hitherto calculation that as to both the strength and the electric resistance any difference does not appear between the undisturbed clay and the remolded clay. The specimen of same shape was made of the fully remolded sample of undisturbed clay, the electric resistance of which is $R u$, with its water content unchanged. If its electric resistance is $R r$, the quantity $W s$ of common water in the undisturbed clay is expressed followingly;

$$
W_{S}=W_{c}(R r / R u)^{3 / 2}
$$

where $W c$ is the water content measured by the ordinary method. As to the clay which was sampled from the extensive area, the author noticed that the strength was deter. mined uniquely with the common water content taken by subtracting the special water content from the water content. It is shown in Fig. 2.10.

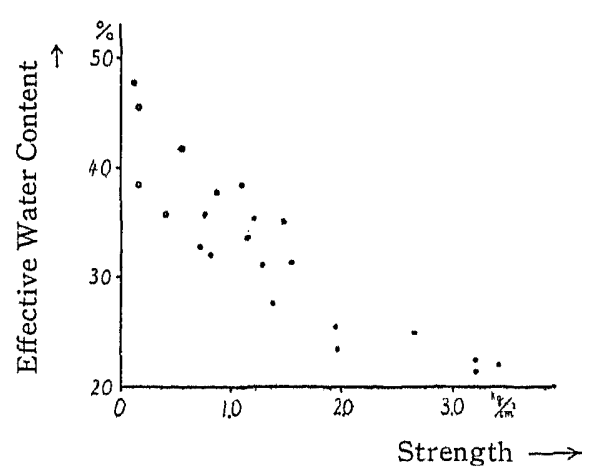

Fig. 2.10 Relation between strength and common water content.

- Undisturbed $\bigcirc$ Remold 
(6) Relation between Strength Recovery and Variation of Electric Resistance

By the experiment so far, we apprehended that the strength of this clay was decided uniquely with the common water content obtained by subtracting the special water content from the water content measured by the ordinary method, and that according to the equation (2.4) the common water content was estimated from the values of electric resistance both in the undisturbed state and in the remolded state. Then, provided that the causes of the phenomenon of strength recovery of the remolded clay in resting are due to the increase of special water and to the decrease of common water during resting, the electric resistance of remolded clay must increase during the resting period. And that, in reality, the electric resistance, similar to the strength, increases in accordance with the proceeding of resting day is shown in Fig. 2.2. Therefore, it may be supposed that the strength recovery due to resting should be caused by the increase of special water content and by the decrease of common water content during the resting period.

(7) Relation between Suction Force and Special Water Content

It was corroborated that, as was aforementioned, the change of nature of clay either by remolding or not was owing to the

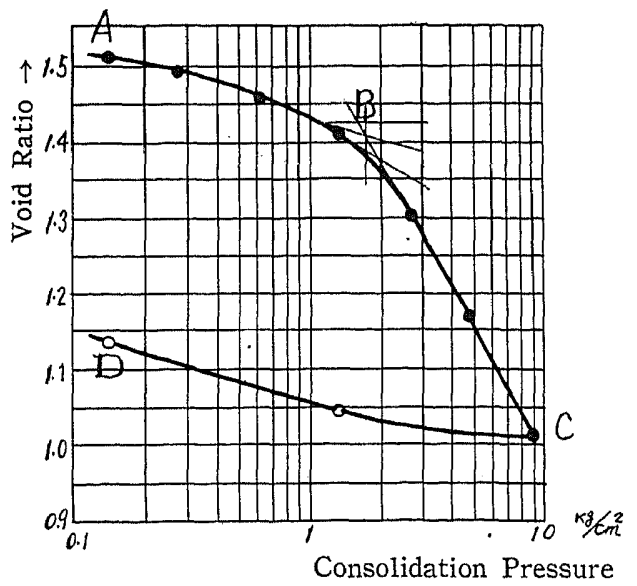

Fig. 2.11 Consolidation curve.

- Undisturbed clay

$\bigcirc$ Remolded clay change of quantity of special water, and consequently to the change of common water content. In this chapter, the relation between such special water content and suction force was studied.

Since consolidation pressure is considered theoretically as suction pressure, the relation between the consolidation pressure and water content can be regarded to be the same as the relation between the suction force and water contained. As shown in Fig. 2.11, the typical example of the relation between the void ratio and the consolidation pressure is expressed $D E C$ in case of the remolded clay and $A B C$ in case of the undisturbed clay. As the consolidation pressure becomes greater, or as the water content becomes diminished, the difference of void ratio between the undisturbed clay and the remolded clay becomes smaller. This suggests the fact that the quantity of special water in the remolded clay increases, as consoliclation proceeds. Decreasing of the sensitivity ratio in accordance with proceeding of the consolidation is ascertained by the experiment. (2) (4) And it is shown as well that the strength ratio between the remolded clay and the clay immediately after remolded goes larger as the degree of liquidity index is higher,* which may be interpreted as follows.

Between the strength $S$ and the water content $W c$, there is a relation,

$$
\log S=\alpha-\beta W c
$$

in which $\alpha$ and $\beta$ are constants. (") Accordingly, if $S$ changes to $(S+\Delta S)$ when $W c$ is diminished by $W c$, we can get the following equation,

$$
\log (S+\Delta S) / S=\beta \Delta W
$$

The quantity of the decrease of common water in order that the special water may increase during resting is considered generally to be in proportion to the water content or to the liquidity index. So, we can be sure that the rate of increase of strength becomes larger as the liquidity index of the specimen is greater. In the experiment of microcalorimeter which will be mentioned after-

* Liquidity index $=$ (Water Content-Plastic Limit) (Liquid Limit-Plastic Limit) 
wards, we see the fact that the difference of special water content between the undisturbed clay and the remolded one becomes small as the consolidation proceeds is no other than the fact that the special water content of the remolded clay increases whereas that of the undisturbed clay remains constant.

The author corroborates in the following experiment that the remolded clay, when its water content decreases so that its special water content increases, approaches to the undisturbed clay. Though, in case of this remolded specimen, its water content is comparatively small, air does not enter into it because the evaporation speed of its soil moisture is slow. The fact that the spacimen contains no air can be corroborated by the measurement of its void ratio. Of the specimens at various water contents air-dried naturally in the atmosphere, the author measured the electric resistance and the obtained result is shown in Fig. 2.12. The

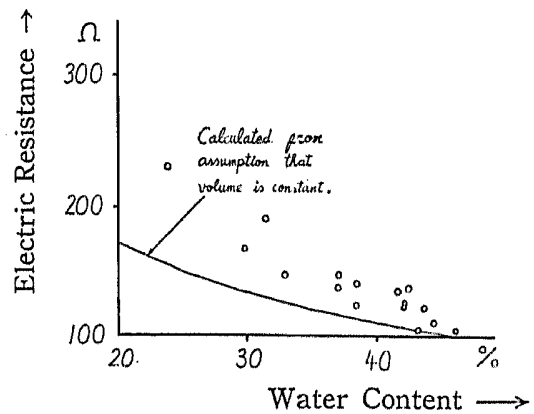

Fig. 2.12 Relation between water content and electric resistance of remolded clay which has low water content.

measured electric resistance shows greater value than that obtained according to the equation (2.1) by assuming that the spacimen should absorb as much air as the volume of water decreased from the initial water content, $46 \%$. Since such a phenomenon means that the decrease of common water which holds electric conductivity is greater than that of water content ordinarily obtained, we ought to consider it as is owing to increasing of the special water content in accordance with decreasing of the water content. Howeve, if the electric conductivity of contained water suffers any change due to the variation of water content, the above-mentioned discussion can not be consisted.

Hence, taking the relation the electric conductivity of contained water and the water content obtained by the experiment, the author confirmed the following fact.

In suspension state where the water content of clay is great and the fraction of clay is small, as has been well-known in the field of electric chemistry of liquid, the electric conductivity of liquid part is in proportion to root of the volume concentration of clay particle. But the author took the result of experiment that, if water content is below $100 \%$, the electric conductivity of liquid part might be considered as constant without having any relation to the water content.

\section{(8) Study on Specific Heat Capacity of Clay by Micro-calorimeter}

In the previous calorimeter-experiments much clay was used, but the quantity obtained by a thin wall sampler from a single location was small. Thus, the measurements of the specific heat capacity of clay at various water contents and the periods of rest were difficult because of the lack of much clay of one kind. To overcome this difficulty, a miniature calorimeter was adopted as shown in Fig. 2.13.

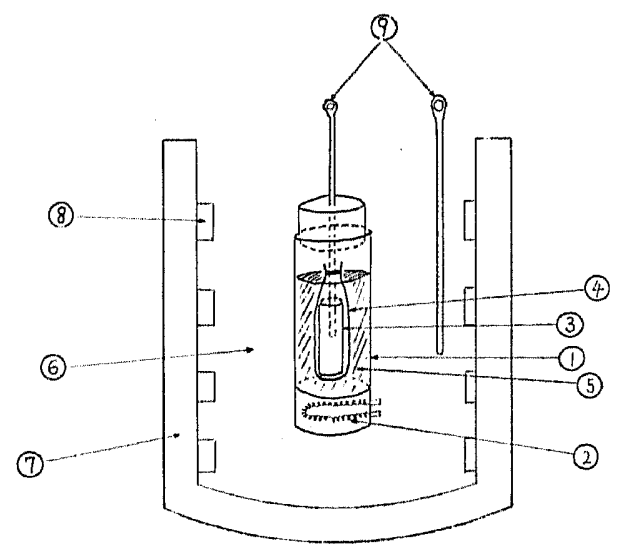

Fig. 2.13 Miniature Calorimeter

(1) Vessel (2) Heater of manganine line

(3) Sample (4) Rubber Sleeve (5) Water of

$120 \mathrm{cc}$ (6) Stilole resign (7) Vacuum bottle

(8) Heater (9) Thermometer 
The apparatus is the same as before used, but is of very small dimensions : the diameter of sample (3) is $3.4 \mathrm{~cm}$ and the length is $8 \mathrm{~cm}$, the diameter of vessel (1) is $5 \mathrm{~cm}$ and the height $25 \mathrm{~cm}$. The heater (2) attached to the bottom is made of manganine line in order to avoid the variation of electric resistance which is apt to arise due to the change of temperature. The electric voltage given in the heater, once having been made constant by the stabilizer, passed through the transformer to $6 \mathrm{~V}$.

The specimen, covered with a rubber sleeve, was submerged in $120 \mathrm{cc}$ of water ${ }^{(i)}$ to ensure equal heating throughout. This miniature vessel was covered with a stirole resin, (6) the outside of which was attached to a thermos. ${ }^{(7)}$

With such an adiabatic method, the flow of heat in the outside cannot be neglected if the temperature of sample rises $5^{\circ} \mathrm{C}$ higher than the room temperature because of the small heat capacity of the vessel and its contents. Consequently, another electric heater ${ }^{(8)}$ was inserted just in the inside of thermos and temperature inside the thermos was kept $2^{\circ} \mathrm{C}$ lower than the temperature of clay specimen, by controlling the voltage.

In such a way, the specific heat capacity of the remolded clay for various resting periods could be taken. The specific heat capacity of water contained in the clay could be determined by deducting the specific heat capacity of clay particles, which had been estimated from the specific heat experiment of clay

Specific Heat Capacity

of Contained Water

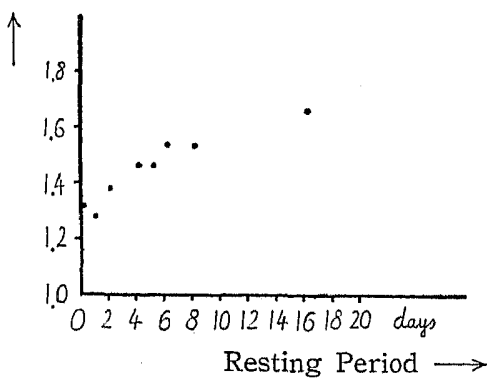

Fig. 2.14 Relation between specific heat capacity of contained water of remolded clay and resting period. particles dessicated at $110^{\circ} \mathrm{C}$ by using this micro-calorimeter. One example of the results of this experiment is shown in Fig. 2.14. The plotted values in Fig. 2.14 express the mean of three measured values. Clearly the specific heat capacity of contained water increases with the period of rest. This indicates that the special water in the clay mentioned above increases and the remolded clay itself, as the time of resting proceeds, approaches to the undisturbed clay.

Next, we measured the specific heat capacity of contained water of the remolded clay and the undisturbed one of various water contents. The result is shown in Fig. 2.15. The relation between the specific heat of the contained water and the water content in the clay state was calculated followingly.

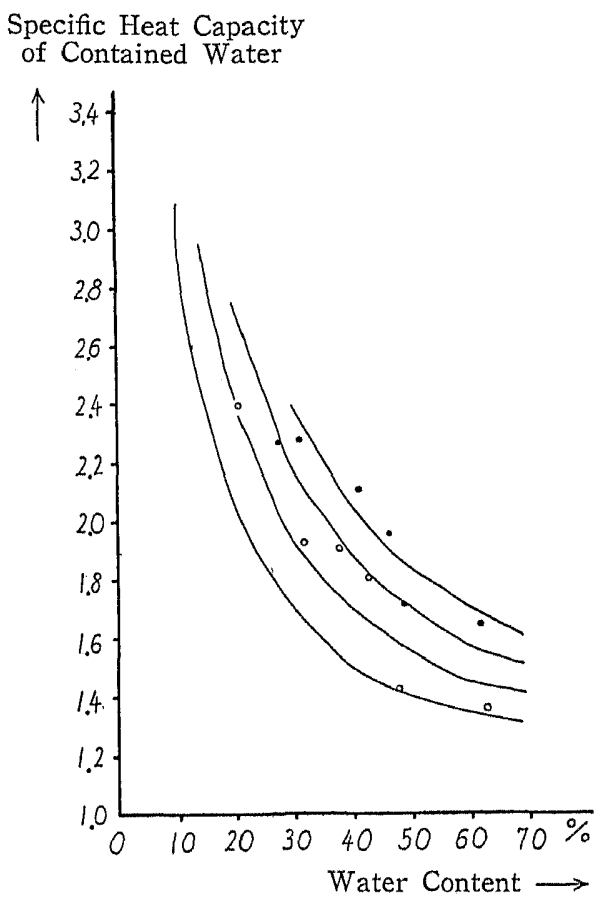

Fig. 2.15 Specific heat capacity of contained water in various water content of remolded and undisturbed clay.

- Undisturbed

Remolded

Assuming that the specific heat capacity of contained water, at $70 \%$ of water content in the clay state, is $1.3,1.4,1.5$ or 1.6 , and that the water lost when the water content 
decreases from $70 \%$ is common water, of which specific heat is 1.0 , in case at any water content $W c$ the mean specific capacity of contained water is accordingly expressed as

$$
\{0.7 \delta-(0.7-W c)\} / W c
$$

where $\delta$ is $1.3,1.4,1.5$ or 1.6 . The measured values were compared with the calculated curves, and the water lost in the undisturbed clay was estimated to be common water. In the remolded clay, however, the increase of specific heat capacity of contained water corresponding to a decrease of water content cannot be explained away only as a result of the loss of common water. This means that in the remolded clay the special water is increasing corresponding to decreasing of water content.

This is also confirmed by the experiment that the strength variation of remolded clay the special water is increasing corresponding to decreasing of water content.

This is also confirmed by the experiment that the strength variation of remolded clay by temperature increases with the proceeding of resting period and approaches to the behaviour of undisturbed clay, as is shown in Fig. 2.16.

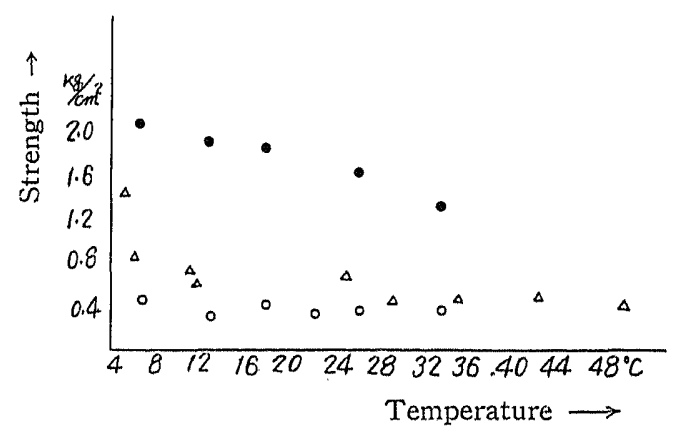

Fig. 2.16 Relation between strength and temperature

- Undisturbed $\bigcirc$ Remolded

$\triangle 30$ days rested after remolding

\section{$\S 3$. Okuramura Clay of Yamagata Prefecture}

\section{(1) Sensitivity}

Taken from the the part of creep type slide region, a sample of this clay might suffer considerable disturbance even in sistu state. Therefore, in the process of sampling, it was cut off by sawing so as not to break its skelton and was conveyed wrapped with vinyl cloth. The author considered the sample which had been rested in the laboratory for two years as the undisturbed clay. In reality, the experimental results of its strength recovery corroborate the appropriateness of his assumption.

Many specimens were made from the fully remolded clay with its water content unchanged and were conserved in polyethilene sack. The shape of sample is cylinder, $2 \mathrm{~cm}$ in diameter and $5 \mathrm{~cm}$ in height. By the strain controlled unconfined compression test, the temporal variation of stress and strain was self-recorded. The rate of compression displacement is about $6.7 \times 10^{--3} \mathrm{~cm} / \mathrm{sec}$. From this record, the stress-strain relation curve can be obtained. One example is shown in Fig. 3.1. Since there is found some fluctua-

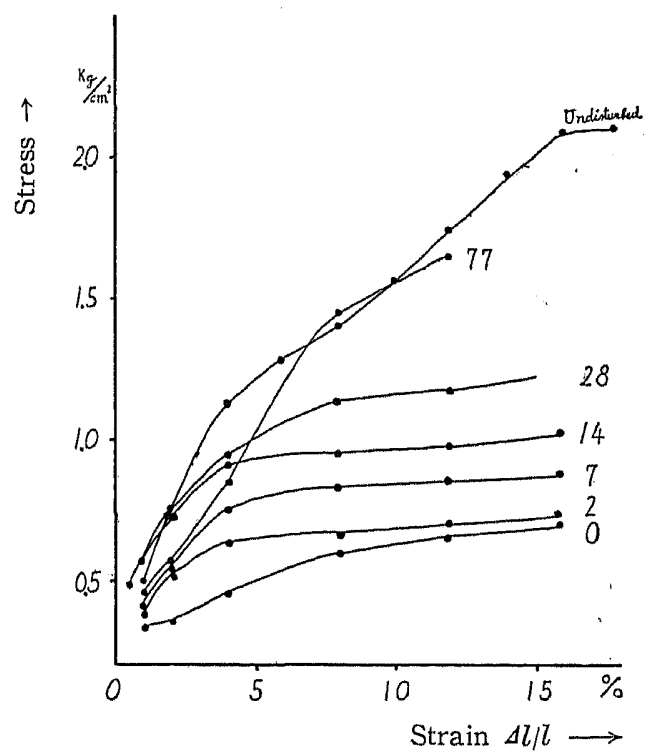

Fig. 3.1 Stress-Strain curves Numbers in the diagram indicate the resting days.

tion in the water content of sample, the relation between the strength and resting day was taken according to the respective classes of its water content. And the result 


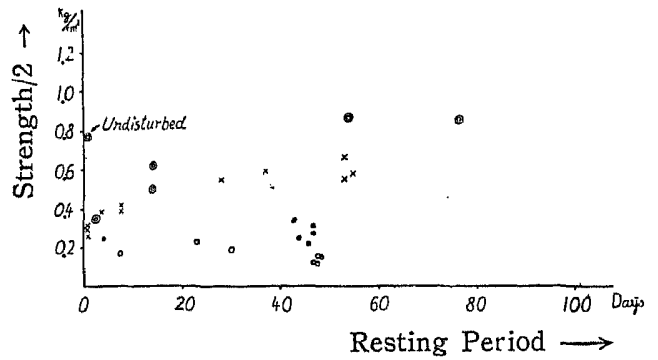

Fig. 3.2 Recovery of strength Water content $36-40 \%$ (O) $41-46 \% \times$ $46-50 \%$ $51-55 \%$

is shown in fig. 3.2. From it, we can perceive that the strength diminished by remolding completely recovers in about two months and Tshebotarioff's sensitivity ratio of the clay after resting is very small. (about 3).

\section{(2) Result of Creep Measurement}

In order to study the reason of sensitivity of this clay as delivered in 3.1, the measurements of void ratio, of the electric potential of particle surface double sheet were taken. The method of measurement is the same way as was performed in 2.2. As its consequence, it was observed that the void ratio and the electrical potential of particle surface double sheet are both alike almostly unchanged by remolding.

Moreover, the electric resistance and the specific heat capacity were measured by the same method as the one mentioned in chapter 2 , and as well any change by remolding was not observed.

Lastly, the author could explain considerably clearly the difference between the undisturbed clay and the remolded clay by the creep measurement. This clay, if given shear stress, occurs stationary flow after some period. (see fig. 3.3)

Whereas the strain of common clay or metal is in proportion to the logarithm of time under the constant shear stress, (i) the strain of this clay is, as is noticed in case of the frozen clay, ice or the remolded clay, in proportion to time.

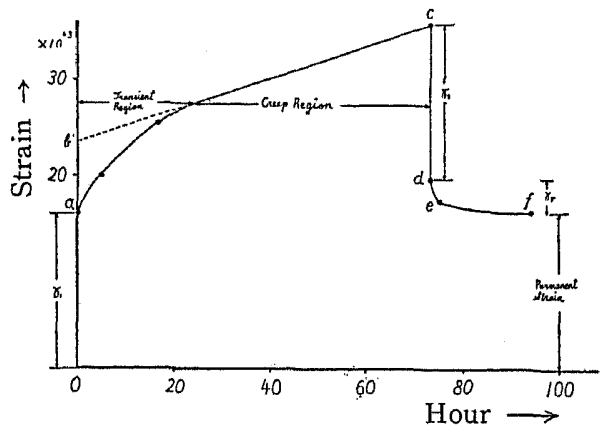

Fig. 3.3 Creep diagram (Normal stress $1.59 \mathrm{~kg} / \mathrm{cm}^{2}$, Shear stress $0.318 \mathrm{~kg} / \mathrm{cm}^{2}$ )

oa: transient strain after shear stress is given

$\mathrm{ab}$ : consolidation region

bc: steady flow region

$c d$ : transient strain after shear is removed

def: retardation region

As the applied stress is varied, the strain rate changes. So, arranging the results of experiment, the author obtained the following equation as the relation between the strain rate $r$ and the stress $\tau$ :

$$
r=A \exp (B \tau)
$$

As this creep occurs caused by the molecular rate and the flow process, by assuming that we may neglect the probability of the molecule removing from the lower position of potential to its higher position, $A$ and $B$, both of which are constant with physical meanings, are expressed as follows :

$$
\begin{aligned}
& A=2 \lambda n \text { (i1) } / h \exp (-E / \text { (ii) }) \\
& B=\lambda s / 2 \text { (ii) }
\end{aligned}
$$

where (ii) equals, KT, $K$ is Boltzmann constant, $T$ absolute temperature, $\lambda$ is average distance projected in the direction of stress between equilibrium positions, $n$ is the number of such process per length, $h$ Plank's constant, $E$ the free energy of activation for the process, and $s$ is the section area of such process vertical to the direction of stress.

Of the remolded clay and the undisturbed, clay, the experimentally obtained $A$ and $B$ are shown in table 3.1.

As is recognized in table $3.1, B$ differs whether in the remolded or in the undisturbed clay. Within $B=\lambda s / 2(\mathbb{1})$, (11) does not change by remolding. Accordingly, that which 
changed is $\lambda s$. That the surface area of clay particle will not be changed is presumable, and that the void ratio of clay will be almostly unchanged too is ascertained by the experiment. Therefore, the values of $\lambda$ and $s$ until multiplied by direction cosine, i.e. the length of a latus of the three-dimentional net work made of the scale-like clay particles and the surface area of the scale-like particle are both unchanged by remolding. So, the fact that the value of $\lambda$ changes means that the cross-angle of scale-like clay particles suffers some change.

If the scale-like particles of the undisturbed clay really form rectangular cross-angle, while those of the remolded clay crosses at random, the calculated ratio of $B$ of both is well consistent with the values obtained by the experiment.

Table 3.1 Values of $A$ and $B$

\begin{tabular}{c|c|c|c|c|c|c|c}
\hline Kind & \multicolumn{3}{|c|}{ Remolded } & \multicolumn{4}{c}{ Undisturbed } \\
\hline $\begin{array}{c}\text { Normal } \\
\text { Stress }\end{array}$ & $0.54 \mathrm{~kg} / \mathrm{cm}^{2}$ & $\begin{array}{r}1.08 \\
-2.00\end{array}$ & $\begin{array}{r}2.13 \\
-2.66\end{array}$ & 0.54 & 1.08 & 1.62 & 2.13 \\
\hline $\mathrm{A}$ & $3.2 \times 10^{-8}$ & $5.0 \times 10^{-9}$ & $1.1 \times 10^{-9}$ & $6.3 \times 10^{-9}$ & $3.2 \times 10^{-9}$ & $1.6 \times 10^{-9}$ & $6.3 \times 10^{-10}$ \\
\hline $\mathrm{B}$ & $7.2 \times 10^{-6}$ & $7.5 \times 10^{-6}$ & $8.3 \times 10^{-6}$ & $1.5 \times 10^{-5}$ & $1.1 \times 10^{-5}$ & $1.3 \times 10^{-6}$ & $1.2 \times 10^{-6}$ \\
\hline
\end{tabular}

\section{(3) Re son of Sensitivity}

According to Table 3.1, it can be observed that the value of $A$ is different whether for the remolded clay or for the undisturbed one, being small in the latter case, and that, as the normal stress increases, it becomes smaller togather in both cases. What is possible to be the cause of the change of $A$ is estimated as is no other than the change of $E$ or $\lambda$ from the equation (3.1). As to what degree $n$ or $\lambda$ can change, the author speculated followingly.

By the measurement of electric resistance, we could ascertain that this clay is isotropic, so that we may consider $s=1 / n^{2}$. Accordingly, $B=\lambda / 2 n^{2}$ (11).

Then, as to the fact that $B$ differs either in the remolded sample or the undisturbed one, two cases can be considered; one in which only $\lambda$ changes by remolding and the

Table 3.2 Values of $\lambda_{u} / \lambda_{r}$, assuming $\lambda$ is variable and $n$ is constant.

\begin{tabular}{c|c|c|c}
\hline $\begin{array}{c}\text { Normal } \\
\text { Stress }\end{array}$ & $0.54 \mathrm{~kg} / \mathrm{cm}^{2}$ & $1.08-2.00$ & $2.13-2.66$ \\
\hline$\lambda_{u} / \lambda_{r}$ & 2.1 & 1.6 & $1.4(4)$ \\
\hline
\end{tabular}

other in which $n$ alone changes by remolding. The variations of both cases were obtained from Table 3.1, and the results are shown in Table 3.2 and Table 3.3, where $n_{u}, n_{r}$ and $\lambda_{u}$, $\lambda$. represent respectively $n$ and $\lambda$ of the undisturbed specimen and the remolded specimen.

Table 3.3 Values of $n_{r} / n_{u}$, assuming $n$ is variable and $\lambda$ is constant.

\begin{tabular}{c|c|c|c}
\hline $\begin{array}{c}\text { Normal } \\
\text { Stress }\end{array}$ & $0.54 \mathrm{~kg} / \mathrm{cm}^{2}$ & $1.08-3.00$ & $2.13-2.16$ \\
$n_{r} / n_{u}$ & $1.45)$ & $1.2(5)$ & 1.2 \\
\hline
\end{tabular}

Provided that the case of the undisturbed clay is standard and $\lambda_{u} n_{u}=1$, the equation (3.1) is expressed as follows:

$$
\log A=13.08-1.08 \times 10^{13} E
$$

where $(1)=4.0 \times 10^{-1.4}$, and $h=6.6 \times 10^{-27}$ are used.

In calculating $\log A$ of the remolded clay for the two cases, one in which $\lambda$ changes in consequence of remolding and the other in which $n$ changes in consequence of remolding, by utilizing table 3.2 and Table 3.3 respectively, some correction shown in Table 3.4 is 
Table 3.4 Correction value of 13.08

\begin{tabular}{c|c|c|c}
\hline $\begin{array}{c}\text { Normal } \\
\text { Stress }\end{array}$ & $0.54 \mathrm{~kg} / \mathrm{cm}^{2}$ & $1.08-200$ & $2.13-2.66$ \\
\hline$\lambda:$ variable & -0.32 & -0.20 & -0.16 \\
$n:$ constant & -0.16 & 0.10 & 0.08 \\
\hline $\begin{array}{c}n: \text { variable } \\
\lambda: \text { constant }\end{array}$ & 0.00 \\
\hline
\end{tabular}

needed to the value 13.08 in the equation (3.2).

By utilizing both table 3.4 and the equation (3.2), we can obtain the value of $E$ from the value of $A$ in Table 3.1. The result taken is shown in Table 3.5 .

Table 3.5 Values of $E$

\begin{tabular}{|c|c|c|c|c|c|c|c|c|}
\hline \multirow{2}{*}{\multicolumn{2}{|c|}{$\frac{\text { Kind }}{\text { Normal Stress }}$}} & \multicolumn{3}{|c|}{ Remolded } & \multicolumn{4}{|c|}{ Undisturbed } \\
\hline & & $0.45 \mathrm{~kg} / \mathrm{cm}^{2}$ & $1.08-2.00$ & $2.13-2.66$ & 0.54 & 1.06 & 1.62 & 2.13 \\
\hline \multirow{2}{*}{$E$} & $\begin{array}{l}\lambda: \text { variable } \\
n: \text { constant }\end{array}$ & $1.88 \times 10^{-12}$ & $1.96 \times 10^{-12}$ & $2.02_{5} \times 10^{-12}$ & \multirow{2}{*}{$1.97 \times 10^{-12}$} & \multirow{2}{*}{$2.00 \times 10^{-12}$} & \multirow{2}{*}{$2.02 \times 10^{-12}$} & \multirow{2}{*}{$2.06 \times 10^{-12}$} \\
\hline & $\begin{array}{l}n: \text { variable } \\
\lambda: \text { constant }\end{array}$ & $1.92_{5} \times 10^{-12}$ & $1.99 \times 10^{-12}$ & $2.04_{5} \times 10^{-12}$ & & & & \\
\hline
\end{tabular}

The value of $E$ obtained as for the creep would represent the quality of micro-particle, and the author will corroborate later in 3.4 that the microparticle plays a main role in the strength of this clay. Therefore, considering that the strength is defined with $E$ and that it is in proportion to $\exp (E / \mathbb{1})$, we can express sensitivity ratio $S_{t}$ followingly:

$$
S_{r}=\exp [(E u-E r) /(\oplus]
$$

in which $E u$ and $E r$ are the values of $E$ of both the undisturbed specimen and the remolded specimen respectively. The calculated values of $S_{T}$ by using the values of Table 3.5 are shown in Table 3.6.

Table 3.6 Values of $S_{T}$

\begin{tabular}{c|c|c|c|c}
\hline Normal Stress & $0.54 \mathrm{~kg} / \mathrm{cm}^{2}$ & $1.08-2.00$ & 2.13 & $\begin{array}{c}\text { Measured } \\
\text { Values }\end{array}$ \\
\hline $\begin{array}{l}\lambda: \text { variable } \\
n: \text { constant }\end{array}$ & 9.3 & 3.5 & 2.4 & 3 \\
\hline $\begin{array}{l}n: \text { variable } \\
\lambda: \text { constant }\end{array}$ & 3.1 & 1.6 & $1.4(5)$ & \\
\hline
\end{tabular}

The result that the volues of $S_{\prime^{\prime}}$ becomes smaller in accordance with the increase of normal stress is well consistent with the other reports. (2) (t)

From the calculation hitherto, the author speculates as to the cause of sensitivity as follows.
The fact that the strength of this clay becomes different either by remolding or not, even at the same water content, or with the same void ratio, may be interpreted due to the reason that in the undisturbed state the arrangements of the scale-like clay particles are in good order and the removal of clay particles are performed under the condition of much activation energy, whereas in the remolded state the arrangements of the scalelike particles are at random, so that they can turn freely and their removals are possible even in the condition of less activation energy. (see Fig. 3.4)

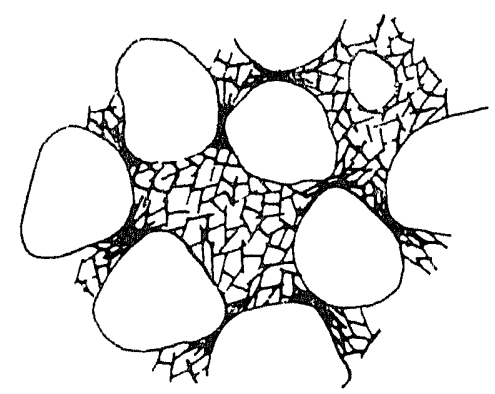

Fig. 3.4 Three dimensional network of clay (after Tan-tyong-kye's paper).

(4) Strength Increase in Resting of the Paste made of Microparticles of Clay alone

As was discussed so far, the sensitivity was explained according to the activation 
energy obtained from the creep phenomenon. However, it might be possible that the larger particle of clay should play the main role in the strength, while the microparticle performs the main role in the creep phenomenon. And, according to Casagrande's theory it is also probable that the clay without silt should not give rise to bond clay so that it should hold no sensitivity.

Then, the author, utilizing the wet mechanical analysis, produced the paste consisted of the microparticles, the particle size of which is below $1 \mu$, which were made by precipitating the larger clay particles and then by evaporating the remnant fluid. And he examined the aspect of the strength increasing of this paste during resting. The examined aspect that the strength of this clay reaches saturation in some two months of resting is similar to that of strength recovery of the original clay. (see Fig. 3.5) This proves nothing but the fact that the microparticle performs an important roles as well in the strength recovery of the original clay.

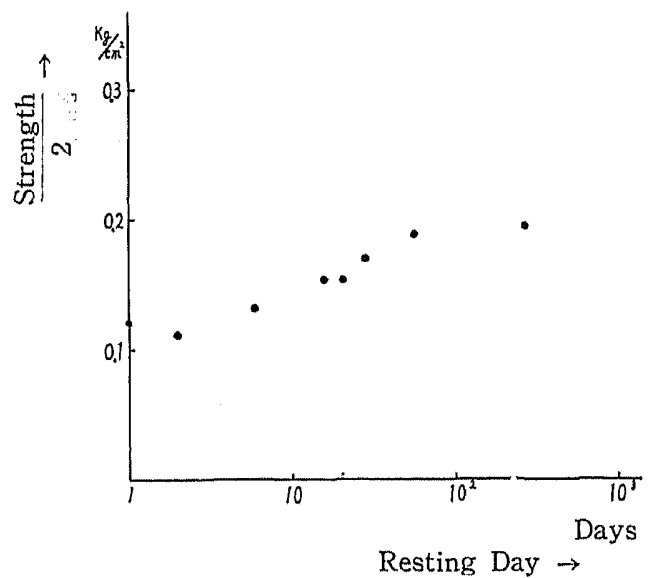

Fig. 3.5 Strength recovery of samples which are constituted with microparticle

Therefore, it may be appropriate that we should explain the sensitivity by the activation energy obtained from the creep phenomenon.

And the author studied experimentally, too, that the strength recovery of the clay paste consisted merely of the microparticles above-

mentioned is not caused by the change of void ratio, and showed the result in Fig. 3.6. According to this figure, the void ratio is regarded as constant without any relation to

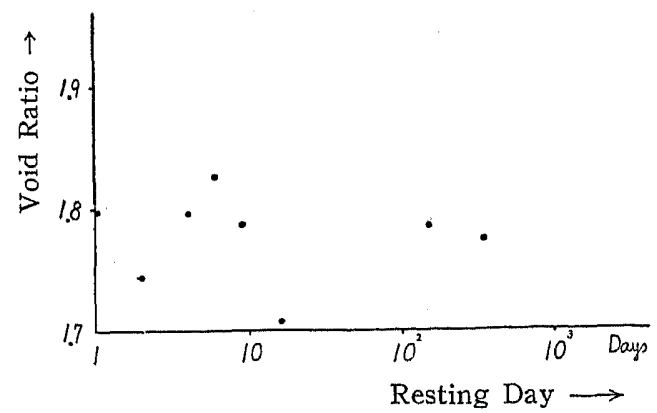

Fig. 3.6 Void ratio-resting day relation (Water content $66-71 \%$ ) of the paste which consists of microparticles smaller than $1 \mu$.

resting day. Then, in Fig. 3.7 and in Fig. 3.8 are shown the water content and the void ratio of each clay paste respectively classified by the particle size by the wet mechanical analysis, when put in the atmosphere and the weight of which keeps equilibrium. Since the condition in which the weight of clay is in state of equilibrium in the atmosphere is below the shrinkage limit, its void ratio ought to increase generally as the particle size becomes small.

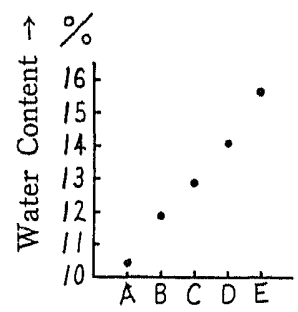

Fig. 3.7 Relation between water content, which is balanced with atmospheric vapour pressure, and particle size $A-1.1 \mu$, $\mathrm{B}-0.78 \mu, \quad \mathrm{C}-0.65 \mu, \quad \mathrm{D}-$ $0.55 \mu, \mathrm{E}-0.42 \mu$.

But Fig. 3.7 represents that the void ratio decreafes as the particle size becomes smaller. Such a fact is just consistent with the result estimated due to the assumption that this 
clay paste forms three dimentional network of the scale-like clay particles of which thickness is uniform. ${ }^{(6)}$ And the fact that, as shown in Fig. 3.8, the water content increases as the particle size becomes small proves that the surface area of clay particle per unit volume of clay increases as the particle size becomes smaller, since the thickness of absorbed water of clay particle which keeps equilibrium with the air can be regarded as uniform.

\section{$\S 4$. Study on Shrinkage Process}

In the previous chapter 3 , we presumed that the strength of consolidation test was decided by the activation energy with which a clay particle passes by the neighbouring clay particle. This fact can be ascertained by the shrinkage process of clay when the soil moisture of which evaporates. Namely it means that, as the strength of clay is larger, its activation energy becomes greater and the shrinkage rate accordingly diminishes. Therefore, even when the evaporation rate of soil moisture remains constant, the clay may differ in the shrinkage rate, in the way of entering of air and in the process of variation of void ratio due to the difference of strength.

Then, the following experiment was performed. Preparing a lot of undisturbed specimens and remolded specimens, we desiccated them naturally in the atmosphere. By varying the desiccation period, we can obtain the specimens in various stages of the process of desiccation. The water content and the void ratio of these specimens in every stages were measured and shown in Fig. 4.1 and Fig. 4.2. As was expected, of Osaka alluvial clay, the void ratio of undisturbed specimen is greater than that of remolded specimen at the same water content. Of Okuramura clay of Yamagata prefecture, however, the void ratio of remolded specimen proves a little greater than that of undisturbed specimen at the same water content. Whereas the strength of Osaka alluvial clay, for instance when its water content is $40 \%$, is about $6.0 \mathrm{~kg} / \mathrm{cm}^{2}$, that of Okuramura clay, when its water

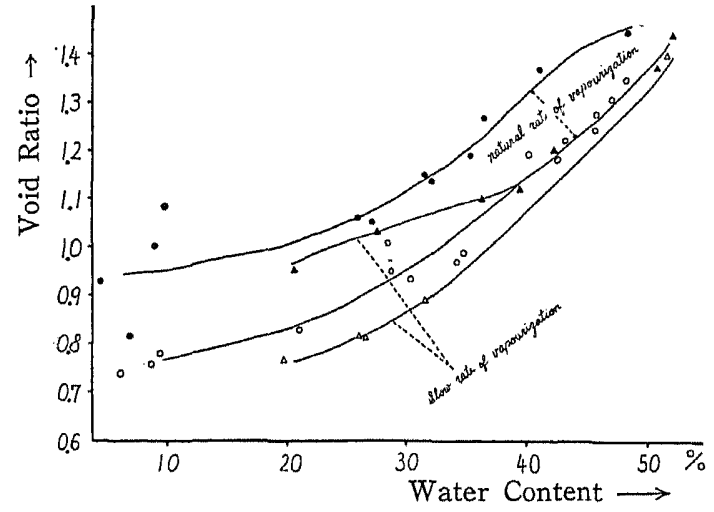

Fig. 4.1 Drying process of Ösaka alluvial clay

\begin{tabular}{|l|c|c|}
\hline & Undisturbed & Remold \\
\hline Natural dry & - & 0 \\
\hline Slow dry & $\Delta$ & $\Delta$ \\
\hline
\end{tabular}

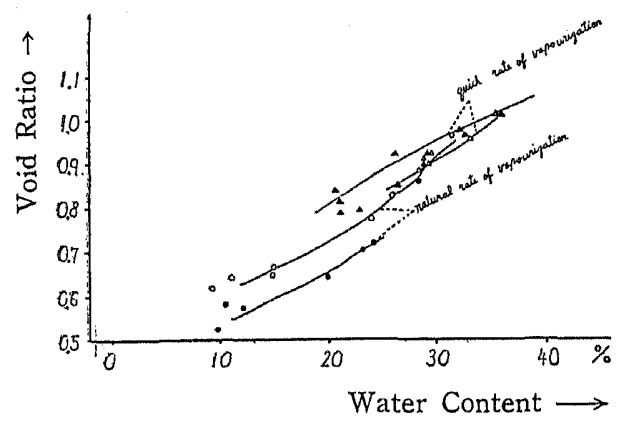

Fig. 4.2 Drying process of Ökuramura clay

\begin{tabular}{|l|c|c|}
\hline & Undisturbed & Remold \\
\hline Natural clay & - & 0 \\
\hline Quick dry & $\triangle$ & $\triangle$ \\
\hline
\end{tabular}

content is the same as the former, is only about $0.8 \mathrm{~kg} / \mathrm{cm}^{2}$ and its activation energy is small too. So, in case of Okuramura clay, since the shrinkage rate can follow the evaporation rate of the soil moisture even in the undisturbed state, the rate of air entering into the clay in the process of desiccation does not differ whether for the remolded specimen or for the undisturbed specimen. Consequently, it may be considered that the void ratio of remolded specimen becomes greater by the air content entered by remold- 
ing than that of undisturbed specimen. To corroborate this idea furthermore, the author put the Osaka clay in the saturated-vapour chamber in the desiccator which contained water in stead of the drying medicine in the bottom, and desiccated it slowly, while Okuramura clay was desiccated rapidly in the drying owen. In consequence, as shown in Fig. 4.1, in the former case there scarcely appears any difference between the remolded specimen and the undisturbed specimen in their void ratio, but the void ratio of undisturbed specimen becomes greater again than that of the remolded one, if below a certain water content. It can be interpreted that, as the water content diminishes, both the strength and the activation energy become greater together and the shrinkage rate of the undisturbed specimen correspondingly decreases too much to follow the evaporation rate of such a degree.

On the other hand, in case of Okuramura clay, the void ratio of undisturbed specimen becomes surely greater. This fact proves that the shrinkage rate is exceeded by the evaporation ratio of soil moisture. Though the shrinkage rate can accompany the evaporation rate in the exterior part of remolded specimen, that rate is so large that the shrinkage in the interior part of the specimen cannot follow. As its consequence, many cracks are produced.

Then the author made the dimension of the specimen smaller or flatened, or keeping the door of the drying oven open to check the evaporation rate and yet such cracks couldn't be prevented. So, by taking the inner, more-or-less uniform shrinking part of specimen, the void ratio and the water content were measured. Though every aspects of the change of water content could not be grappled, it can yet be observable that the void ratio of remolded specimen becomes smaller, compared with that of the undisturbed specimen at the same water content. (see Fig. 4.2)

\section{§5. Conclusion}

By taking as sample both Osaka alluvial clay which is called Kaolinite and the clay gathered from Yamagata prefecture, Okuramura land creep region, the author studied as to the sensitivity. As the result, we could comprehend that it was explained due to the special water in case of the former clay while in case of the latter clay it was explained according to the difference of the arrangement of the scale-like particles.

\section{Acknowledgement}

This author sincerely wishes to express his cordial thanks to Dr. K. Sassa, Prof. of Geophysical Institute of Kyoto Univ., and to Dr. S. Murayama, Prof. of Civil Engineering Institute of Kyoto Univ., for their guidances and instructions all the time throughout this study.

\section{References}

(1) O. Morretto:

"Effect of Natural Hardening oh the Unconfined Compression Strength of Remolded Clay.", Proc. 2nd Int. Conf. Soil Mech. and Found. Engr. vol. 1, pp. 137

(2) P. L. NEWLAND et al:

"A Study of the Sensitivity Resulting from Consolidation of a Remoulded Clay.", Proc. 4th Int. Conf. Soil Mech. and Found. Engr. vol. 1, pp. 83

(3) S. Murayama et al:

The Effect of the Moisture Content on the Strength of an Alluvial Clay., Disaster Prevention Research Inst. Bul. No. 12 pp. 5

(4) Y. IsHII et al:

Researches on the Engineering Properties of Alluvial Clays., Trans. of the Japan Soc. of Civil Engr. No. 30. (1955).

(5) S. S. VIALOV et al:

"Rheological Processes in Frozen Soils and Dense Clay.", Proc. 4th Int. Conf. Soil Mech. and Found. Engr. vol. 1 pp. 120

(6) T. V. LAMBE:

"The Structure of Inorganic Soil.", Proc. A.S.C.E. vol. 79 Separate No. 315 